\title{
An loT Based Car Parking System for Supermarkets
}

\author{
Prasenjeet Damodar Patil' and Pradip Ram Selokar ${ }^{2}$ \\ ${ }^{1}$ Associate Professor, Department of Electronics Engineering, Sanjay \\ Ghodawat University, Kolhapur, (MS), India \\ ${ }^{2}$ Assistant Professor, Department of Electronics and Communication Engineering, \\ Shri Ramdeobaba College of Engineering and Management, Nagpur (MS), India.
}

\begin{abstract}
One of the challenge faced by people living in metropolitan cities of India is parking of cars at supermarkets, shops, theater, hotels, stadiums etc. This problem becomes more serious during weekends and holidays. Solutions provided in earlier work includes, image processing based automatic number plate recognition system, use of RFID tags, QR code, vehicle tracking etc. These solutions are not feasible to implement as they suffer from security as well as implementation challenges or are not cost effective. In this paper, an IoT based solution for parking of cars at supermarkets is presented using NodeMCU ESP8266. Two ultrasonic sensors are placed in each parking slot for checking the car occupancy. An android mobile app is developed which is used for the purpose of displaying available slots, dynamic fare and booking of available slot for the user selected time period. User information is collected, once a particular slot is chosen by the user. A code is generated for each booking and the same is used for validation at the entrance gate of the parking. Complete details are stored on the cloud. The prototype of the system has been developed and tested for booking slot using ESP8266 and google firebase as cloud hosting service. We found that above system is more efficient and economical for booking of parking slots at supermarkets.
\end{abstract}

KEY WORDS: IOT, NODEMCU ESP8266, RFID TAG.

\section{INTRODUCTION}

Automatic parking slot booking system for cars has been area of interest of many researchers. People often find difficulties in parking vehicle at public places. Many a times, it happens that, if the slot is already preoccupied, it not only wastes time, but also causes traffic jam at places like theater, play grounds, supermarkets etc. Conventional systems used in India are based on pay and park system. In this system, person has to pay money to park his vehicle at any available slot. This

\section{ARTICLE INFORMATION}

*Corresponding Author: prasenjeet.patil@gmail.com Received 14th Oct 2020 Accepted after revision 22nd Dec 2020 Print ISSN: 0974-6455 Online ISSN: 2321-4007 CODEN: BBRCBA

Thomson Reuters ISI Web of Science Clarivate Analytics USA and Crossref Indexed Journal

\section{Clarivate
Analytics}

NAAS Journal Score 2020 (4.31)

A Society of Science and Nature Publication,

Bhopal India 2020. All rights reserved.

Online Contents Available at: http//www.bbrc.in/

Doi: http://dx.doi.org/10.21786/bbrc/13.14/103 system suffers from major problem of manually finding the vacant slot for parking car. In parking system with large number of parking slots, sometimes it becomes very difficult to locate the car. Human assisted parking system are available, but still it is difficult to maintain the database of parked car. Such, system also suffers from vulnerability of theft.

With the ever increasing population in big cities \& keeping the future demand for automatic parking of cars, Internet of Things (IoT) seems to be promising technology. IoT relies on sensors connected to IoT platforms $\mathrm{Ct}$ sending the data to cloud trough IoT Gateway. It has been said that, limitless devices can be connected through IoT. With IoT enabled technologies it is possible to acquire data, perform data analysis as well as have control of devices. Wide range of IoT platforms are available which includes Arduino, Intel Edison, ESP, Raspberry Pi, Particle, Adafruit series etc. Many of these boards are equipped with features like, large number of I/0 pins, high speed 
processor, inbuilt Wi-Fi module, re-configurability, operating system, portability, inbuilt memory, support to external memory \&t portability. This paper explains the system developed using ESP8266 which is NodeMCU. It has inbuilt Wi-Fi module and it is easy to program. Other useful features of ESP8266 include small size, low power consumption (3.3V), access point (AP) \&t station node, SPI, UART and I2C pins.

Literature survey: Majority of parking system in India are pay and park based systems, which suffers the problems discussed earlier. Researchers in other countries have tried to provide solution to this problem. S. Banerjee et. al. demonstrated image processing approach for real time car parking system to detect the availability of parking slot. Mohammed Y Aalsalem et. al. has developed car parking and management system using license plate recognition for car parking at university. The system was developed to monitor the cars of students and staff in the parking slot. Vaibhav Hans et. al. proposed cloud based solution for car parking and reservation system. This system was based on image detection camera to detect the car and mobile application was developed for parking slot booking. Ricard Garra et. al. developed a simple pay by phone parking system in which booking can be done by calling the parking vendor. Mahendra B $\mathrm{M}$ et. al. developed IoT based car parking system using sensor and Raspberry Pi 3b. Andre Braga Reis et. al. in their paper introduced use of IEEE 802.11p and WAVE technology to track the vehicles.

They have presented comprehensive study on formation of roadside cars by forming network. Chih-Cheng Huang et. al has presented novel approach using GMR sensor, microprocessor and inductive data transfer module to position the vehicle in parking lot. Archika Singh et. al., developed prepaid car parking system using RFID and HDL. The HDL code was simulated in Xilinx Vivado 15.4. Zahid Mahmood et. al. presented fully automated car parking system using image processing. It is consisting of license plate extraction and face detection of driver. A bar code printed ticket was provided at the entrance gate to each driver and payment has to be done at terminal gate. Face recognition \& bar code are mapped with the driver using image processing. Other approaches includes use of Arduino, use of drone and line following robot for detection of parking slots. Enamul Hoq et. al. presented QR code based approach for car parking system. Yugesh KC et. al. presented car parking system using location service. In this system mobile sensing unit is fixed in each car and detecting device is placed in each slot. Recently, JOSÉ AZEVEDO et. al. presented evaluation of different strategies of vehicle coordination for different parking scenarios.

\section{METHODOLOGY}

Figure 1 shows the block diagram of IoT based car parking system. The system is divided into two modules. The first module is placed in parking slot to detect, whether parking slot is occupied or not. It is consisting of NodeMCU ESP8266 to which, stepper motor, two ultrasonic sensors \&t two LED's are connected. The information acquired from it is transmitted to the second module which acts as a soft access point. The second module is consisting of NodeMCU ESP8266 interfaced to Arduino Uno, which is connected to internet through RJ45 port. The main task of this module is to collect the information and send it to the cloud. The data collected on the cloud is linked with android app, through which users can check the booking status as well as book the slot. An admin access is provided in the android app to the parking vendor which is used to track the parking details. The station module is battery powered, while access point module is line powered.

Figure 1: Block diagram of Car Parking System

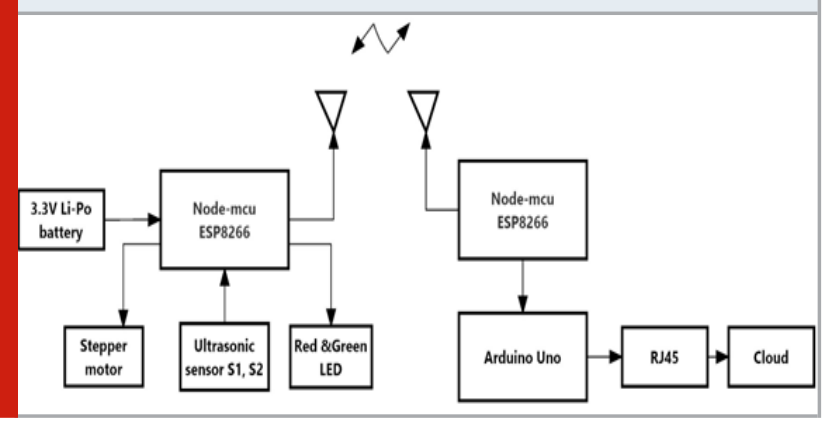

Working: The first and foremost task is to detect the availability of vacant slots accurately. In order to do that, two ultrasonic sensors, one at top wall \&t one at bottom are kept in each parking slot. The distance threshold is calculated by taking difference between the two read values from the sensors to determine whether the slot is occupied or not. Pair of LED's are used to indicate status of the slot. Depending upon the threshold value either the Green or Red color led is turned ON or OFF. For vacant slot Green LED is turned 'ON' and if the slot is occupied Red LED is turned ON and vice-versa. A stepper motor is interfaced with ESP8266 using A988 module, which is used to lock \&t unlock the parking slot, thereby providing safety to car against theft as well chances of false occupancy by other car. As shown in figure 2, this ESP8266 module acts as a Station node and relays the information of slot to Access point. The second ESP8266 module interfaced to Arduino Uno shown in fig.3 acts as Soft Access point (AP). This module is connected to internet via Ethernet cable. The prime purpose of this module is to collect the information from all stations and forward it to cloud.

The third part of the system shown in fig. 4 is an android app designed using android studio. This app provides interface to user as well as parking slot vendor. By using this app, user can check the status of available slots and can book it, if it is available. At the time of booking, user information like Name, Phone number, selection of time period for which slot has to be booked \& car number is collected. On successful booking, a four digit PIN is provided to the user. The complete information is stored on google firebase which is a free cloud hosting service. 
Figure 2: Circuit diagram of Station node

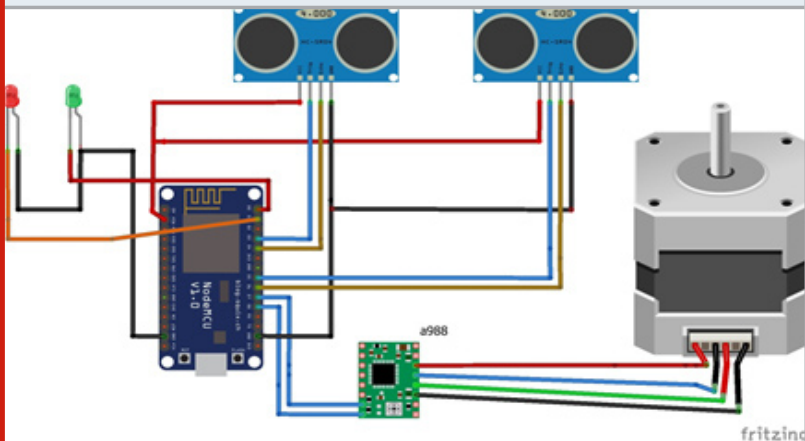

Figure 3: Circuit diagram of Access Point (AP)

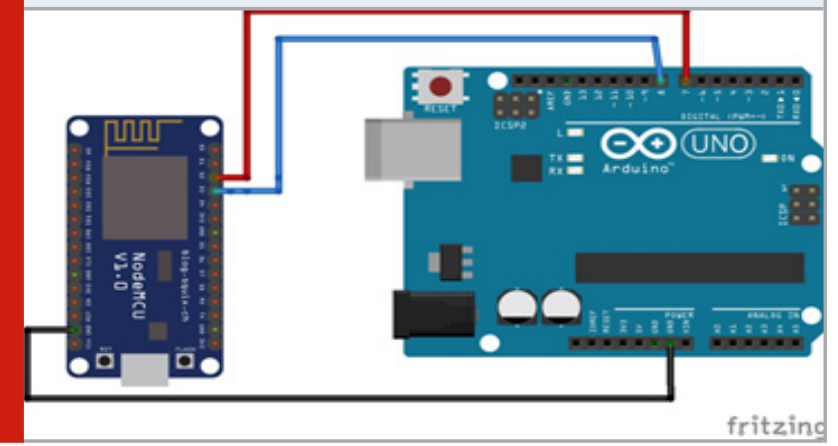

Figure 4: Android app for Parking slot booking

to $\mathrm{OO}$

Q411:57

\section{IoT based Car Parking System}

\section{Enter Full name}

Enter Car number

\section{Input date and time}

CHECK FOR AVALABLE SLOTS

MAKE PAYMENT

Once the slot is booked, it will be shown as locked or not available to other users on app. When the user arrives at supermarket gate, he has to validate the four digit pin against the car \& slot number. Access will be granted only if the four digit PIN matches with the car number. After the validation process is complete, database on the cloud is updated \& control information is sent from cloud to the station module. After receiving the control information, the stepper motor connected to station module opens the door of parking slot. Once the slot is occupied, red color led is turned ON. Again the information is updated on the cloud and station node is programmed to go in deep sleep to save battery power. The person at the gate will be having the same app with higher privileges to provide access control, in case of manual control is required.

\section{RESULTS}

The prototype of IoT based car parking system has been developed and tested in the laboratory. The results obtained meet the desired objectives. It has been found that, the use of NodeMCU, solves the majority of problems that occur in manual parking system. The benefits of smart parking system go well beyond avoiding wasting of user time in searching for vacant parking slot.

\section{CONCLUSION}

It can be concluded that, the designed system is better than pay and park based system, where it is difficult to track the number of users per day. It not only solves the problem of parking, but also keeps the record of everything from user information to payment made. In the future, car tracking can be implemented to trace the car before arrival. Interfacing of payment gateway can be included, by which PIN will be generated only after successful payment is done. Dynamic fare system and early arrival and early departure can be considered as critical problem in future work. With the advancement of technology in the field of IoT platforms, ESP8266 can be replaced with NodeMCU with long range.

\section{REFERENCES}

Andre Braga Reis, Susana Sargento, and Ozan K. Tonguz. Smarter Cities With Parked Cars as Roadside Units. IEEE TRANSACTIONS ON INTELLIGENT TRANSPORTATION SYSTEMS, 2018.

Archika Singh, Mumin Sajad Shawl, Shikha Bathla, Nidhi Gaur, Anupama Mehra, "RFID AND HDL BASED PRE-PAID CAR PARKING SYSTEM,” in 2nd International conference on Electronics, Communication and Aerospace Technology (ICECA 2018).

Chih-Cheng Huang, Chun-Liang Lin, Jia-Jing Kao, Jun-Jay Changand Geeng-Jen Sheu. Vehicle Parking Guidance for Wireless Charge Using GMR Sensors, IEEE TRANSACTIONS ON VEHICULAR TECHNOLOGY, 2018.

Enamul Hoq, Sajib Paul, Md. Tarek Ur Rahman, "Development of QR-code based Smart car parking system," in 5th International conference in Advances in Electrical Engineering(ICAEE),26-28 September 2019. Faris Alshehri, A. H. M. Almawgani, Ayed Alqahtani, Abdurahman Alqahtani, "Smart Parking System for Monitoring Cars and Wrong Parking,” I.E.E.E 2019. JOSÉ AZEVEDO , PEDRO M. D’OREY , (Member, IEEE), AND MICHEL FERREIRA. High-Density Parking for Automated Vehicles: A Complete Evaluation of 
Coordination Mechanisms, IEEE Access 2020.

Mahendra B M, Dr Savita Sonoli, Nagaraj Bhat, "IoT Based Sensor Enabled Smart Car Parking for Advanced Driver Assistance System," in 2nd IEEE International Conference On Recent Trends in Electronics Information \& Communication Technology (RTEICT), May 19-20, 2017.

Meherin Hossain Nushra, Quazi Ashikur Rahman, S.M.Faiaz Mursalin, Nashita Binte Asad, "Smart Car Parking with the assistance of Line Following Robot," in International Conference on Sustainable Technologies for Industry 4.0 (STI), Dhaka 2019.

Mohammed Y Aalsalem, Wazir Zada Khan, Khalid Mohammed Dhabbah, "An Automated Vehicle Parking Monitoring and Management System Using ANPR Cameras," in ICACT2015, July 1-3, 2015.

Ms.Sayanti Banerjee, Ms. Pallavi Choudekar, Prof .M.K.Muju, "Real Time Car Parking System Using Image Processing," IEEE 2011.
Ricard Garra, Santi Martınez, and Francesc Seb. A Privacy-Preserving Pay-by-Phone Parking System, IEEE TRANSACTIONS ON VEHICULAR TECHNOLOGY, DECEMBER 2016.

Tasato Yuske, Zacharie Mbaitiga, "Development of Drone Detecting Free Parking Space for Car Parking Guidance," in International Conference on Image Processing, Computer Science and Information technology, Shangia, 2019.

Vaibhav Hans, Parminder Singh Sethi, Jatin Kinra, “An Approach to IoT based Car Parking and Reservation system on Cloud," IEEE 2015.

Yugesh KC, Chang-Soon KANG, "A Connected Car-based Parking Location Service System," in IEEE International Conference on Internet of Things and Intelligence System (IoTaIS) 2019.

Zahid Mahmood, Ossama Haneef, Nazeer Muhammad, Shahid Khattak. Towards a fully automated car parking system, Vol. 13 Iss. 2, pp. 293-302, IET Journal of Intelligent Transport Systems, 2018. 